\title{
Genetic Relationship among Nepalese Rice Landraces and Cultivars based on RAPD Markers
}

\author{
Bal K. Joshi*, Hari P. Bimb, David Kansakar and Ekta Ghimire
}

Biotechnology Unit, NARC, PO Box 1136 Kathmandu, Nepal

* Corresponding author: Email: joshibalak@rediffmail.com

\begin{abstract}
Genetic information of any genotype is necessary to manage and utilize them in conservation and breeding program. A total of 28 RAPD markers were used to relate the genetic structure among 50 Nepalese rice genotypes consisting of 29 landraces, 12 breeding lines and 9 released cultivars. Some of them are aromatic and blast resistance. Only four primers (P41, P60, P109 and P141) amplified the DNA of these genotypes with scorable bands. Primer 60 produced the highest number of bands (8). The highest number of present bands (6) was shown by primer 41 in 10 rice genotypes. Grouping of these genotypes based on the adaptation to agro-climatic zone was not observed, probably due to low percentage coverage of genome by four primers. Most of the genotypes grouped in two clusters. Kali Marsi and IR-24 formed separate individual cluster. Mansara and Jarneli were the most similar landraces (0.96). Churenodhan and Pranpyuri were the most closely related with Masuli. Only one genotype NR-285-18 has fallen in the first quadrant by principal component (PC) analysis and the fourth quadrant was empty. The highest contribution in PC1 was from the second band of primer 41. This RAPD information can be used for selecting lines and for blast resistance breeding.
\end{abstract}

Key words: Genetic distance, rice, RAPD

\section{Introduction}

Nepal is rich in rice genetic resources [1,2]. Knowledge on genetic diversity contributes significantly for the better management and utilization of these resources. Diversity analysis with the help of molecular markers provides reliable information which can be utilized for breeding purposes. RAPD
(Randomly Amplified Polymorphic DNA) [3] markers though dominant markers, provides fast, reliable and cost effective determination of genetic diversity in plant varieties, breeding lines and accessions [4-6]. In RAPD, a single random primer is added to the template DNA and subjected to polymerase chain reaction (PCR). This simple but effective method of revealing polymorphism is cheap and 
universally applicable [7, 8]. The indica and japonica cultivars are classified into separate groups by cluster analysis using RAPD [5]. We studied the genetic diversity of rice particularly adapted to mid and high hills using RAPD markers to support for effective management and utilization of rice genetic resources.

\section{Materials and methods}

\section{a. Plant materials and plant DNA extraction}

The rice genotypes analyzed are given in Table 1. A total of 50 rice samples consisting of landraces, breeding lines and released cultivars were used. DNA was extracted employing the Modified CTAB method of [9].

\section{b. DNA amplification}

For RAPD analysis 28 decamer primers were tested (Table 2). Amplification was carried out in a $10 \mu \mathrm{l}$ reaction volumes consisting of
$10 \mathrm{mM}$ Tris-HC1 pH 8.3, 2mM $\mathrm{MgCl}_{2}$, $0.2 \mathrm{mM}$ dNTPs, $1 \mathrm{mM}$ primer, 0.35 unit of Taq DNA polymerase and $1 \mathrm{ng}$ of total DNA as template. The amplification reaction was carried out in PTC-100 thermocycler (MJ Research, USA). The first cycle consisted of denaturation of template DNA at $93.5^{\circ} \mathrm{C}$ for 1 min, primer annealing at $36^{\circ} \mathrm{C}$ for $2 \mathrm{~min}$ and primer extension at $72^{\circ} \mathrm{C}$ for $3 \mathrm{~min}$. In the next 44 cycles, the three steps of first cycle were repeated. In the last cycle it is hold at $72^{\circ} \mathrm{C}$ for $7 \mathrm{~min}$ and then at $4^{\circ} \mathrm{C}$ for $3 \mathrm{~min}$. PCR products were separated on a $1.8 \%$ agarose gel using TAE buffer. The gels were run for $2.5-3 \mathrm{hr}$ at $70 \mathrm{~V}$ and stained with ethidium bromide. DNA fragments were visualized under UV light and photographed using Gel Doc system.

Only the four primers amplified the DNA of test lines. Polymorphisms were scored for the presence or absence of bands on a $1 / 0$ basis and data analyzed using the NTSYS-pc software [10]. 
Table 1. Rice landraces, cultivars and breeding lines used in this study.

\begin{tabular}{|c|c|c|c|c|c|}
\hline S.N. & Genotype & Collection site & Altitude, $\mathrm{m}$ & $\begin{array}{l}\text { Collection } \\
\text { year }\end{array}$ & Remarks \\
\hline 1 & Krishnabhog & Achham & 1000 & 1985 & Landrace \\
\hline 2 & Thapachini & Bajura & 1768 & 1995 & Landrace \\
\hline 3 & Tauli & Bhojpur & 1219 & 1987 & Landrace \\
\hline 4 & Tunde dhan & Dailekh & 1400 & 1995 & Landrace \\
\hline 5 & Rato dhan & Dadeldhura & 1585 & 1995 & Landrace \\
\hline 6 & Hansraj & Dadeldhura & 1128 & 1995 & Landrace \\
\hline 7 & Mansara & Dadeldhura & 1128 & 1995 & Landrace \\
\hline 8 & Chureno dhan & Dang & 2120 & 1985 & Landrace \\
\hline 9 & Anpjhutte & Gorkha & 1981 & 1988 & Landrace \\
\hline 10 & Jarneli & Gulmi & 2000 & 1998 & Landrace \\
\hline 11 & Bhuwa dhan & Humla & 1970 & 1985 & Landrace \\
\hline 12 & Jhul dhan & Humla & 1350 & 1985 & Landrace \\
\hline 13 & Pahele & Kaski & 1075 & 1998 & Landrace \\
\hline 14 & Radha-7 & Kaski & 1040 & 1998 & Released \\
\hline 15 & Pakhe & Lamjung & 1920 & 1988 & Landrace \\
\hline 16 & Pranpyuri & Lamjuing & 1996 & 1988 & Landrace \\
\hline 17 & Madise & Lamjung & 1524 & 1988 & Landrace \\
\hline 18 & Kali marsi & Mugu & 2600 & 1985 & Landrace \\
\hline 19 & Ghaiya dhan & Mugu & 2380 & 1985 & Landrace \\
\hline 20 & Dhokro & Mugu & 2350 & 1985 & Landrace \\
\hline 21 & Maine pokhreli & Mustang & 1400 & 1985 & Landrace \\
\hline 22 & Lekali dhan & Myagdi & 1800 & 1985 & Landrace \\
\hline 23 & Hanse & Sallyan & 1200 & 1992 & Landrace \\
\hline 24 & Pale dhan & Sindupalchok & 1500 & 1985 & Landrace \\
\hline 25 & Bageri dhan & Solukhumbu & 1707 & 1989 & Landrace \\
\hline 26 & Jethobor & Tanahun & 1250 & 1988 & Landrace \\
\hline 27 & Pokhara masino & Tanahun & 1250 & 1988 & Landrace \\
\hline 28 & Chananchur & Udaypur & 1829 & 1989 & Landrace \\
\hline 29 & Lalshar & Udaypur & 1829 & 1989 & Landrace \\
\hline 30 & NR10315-145 & ABD, Khumaltar & & & Breeding line \\
\hline 31 & NR10286-6 & ABD, Khumaltar & & & Breeding line \\
\hline 32 & Manjushree-2 & ABD, Khumaltar & & & Released \\
\hline 33 & NR10375-20 & ABD, Khumaltar & & & Breeding line \\
\hline 34 & Khumal-11 & ABD, Khumaltar & & & Released \\
\hline 35 & NR10353-8 & ABD, Khumaltar & & & Breeding line \\
\hline 36 & NR285-18 & ABD, Khumaltar & & & Breeding line \\
\hline 37 & NR10276-15 & ABD, Khumaltar & & & Breeding line \\
\hline 38 & NR10414-25 & ABD, Khumaltar & & & Breeding line \\
\hline 39 & NR10414-34 & ABD, Khumaltar & & & Breeding line \\
\hline 40 & Taichung-176 & ABD, Khumaltar & & & Released \\
\hline 41 & Jumli White & ABD, Khumaltar & & & Landrace \\
\hline 42 & Chandan nath-1 & ABD, Khumaltar & & & Released \\
\hline 43 & Chandan nath-3 & ABD, Khumaltar & & & Released \\
\hline 44 & NR10276-9 & ABD, Khumaltar & & & Breeding line \\
\hline 45 & NR10285-29 & ABD, Khumaltar & & & Breeding line \\
\hline
\end{tabular}




\begin{tabular}{|l|l|l|l|l|l|}
\hline S.N. & Genotype & Collection site & Altitude, $m$ & $\begin{array}{l}\text { Collection } \\
\text { year }\end{array}$ & Remarks \\
\hline 46 & Sabitri & NRRP, Hardinath & & & Released, BR \\
\hline 47 & IR-24 & NRRP, Hardinath & & & Released, BR \\
\hline 48 & A57-115-8 & NRRP, Hardinath & & & $\begin{array}{l}\text { Breeding line, BDI (3 } \\
\text { gene pyramid) }\end{array}$ \\
\hline 49 & CO39 & NRRP, Hardinath & & & Breeding line, BS \\
\hline 50 & Masuli & NRRP, Hardinath & & & Released, BS \\
\hline
\end{tabular}

Note: ABD, Agriculture Botany Division. NRRP, National Rice Research Program. B, Blast. R, Resistant. S, Susceptible. DI, Differential line.

Table 2. Details of RAPD primers used in this study.

\begin{tabular}{|c|c|c|c|c|}
\hline S.N. & Primer & Sequence & Band scored & Remarks \\
\hline 1 & P36 & GGGGGTCGTT & - & \\
\hline 2 & $\mathrm{P} 40$ & GGCGGACTGT & - & \\
\hline 3 & $\mathrm{P} 41$ & GAGTGCGCAG & 6 & Rice genome \\
\hline 4 & $\mathrm{P} 42$ & CCGGACTGAG & - & \\
\hline 5 & P48 & GAAGGCGCGT & - & \\
\hline 6 & P52 & GGCACCACCA & - & \\
\hline 7 & P60 & CATCGGCCCT & 8 & \\
\hline 8 & P109 & TGGCCACTGA & 3 & \\
\hline 9 & P141 & GTGATCGCAG & 7 & Operon Tech \\
\hline 10 & P142 & CAATCGCCGT & - & \\
\hline 11 & P144 & CAGCACCCAC & - & \\
\hline 12 & P165 & CTGACGTCAC & - & \\
\hline 13 & P169 & AGTCGACGCC & - & \\
\hline 14 & P181 & ACGGACGTCA & - & \\
\hline 15 & P189 & TGGGTCCCTC & - & Operon Tech \\
\hline 16 & P191 & CTGCGCTGGA & - & \\
\hline 17 & P194 & AGGCCCGATG & - & \\
\hline 18 & P197 & GACCCCGGCA & - & \\
\hline 19 & P198 & GCCTGGTTAC & - & \\
\hline 20 & P202 & CGCAGACTTG & - & TAG 91:65-667.'95. Lentil \\
\hline 21 & $\mathrm{P} 205$ & GCCGTGAAGT & - & TAG 91:65-667.'95. Lentil \\
\hline 22 & P209 & GGCGTCGGGG & - & TAG 91:65-667.'95. Lentil \\
\hline 23 & P217 & GGGTTGCCGT & - & TAG 85:937-95.'93.Vicia faba \\
\hline 24 & $\mathrm{P} 222$ & GTCACCCGGA & - & TAG 85:937-95.'93.Vicia faba \\
\hline 25 & $\mathrm{P} 225$ & AGTGGTCGCG & - & \\
\hline 26 & $\mathrm{P} 232$ & GCGCATTAGA & - & Bio/Tec 10:686-690. Conifer \\
\hline 27 & $\mathrm{P} 270$ & AGCCAGTTTC & - & TAG 85:190-196.'92. Brassica \\
\hline 28 & P292 & CAAACGGCAC & - & TAG 86:788-794.'95. Alfalfa \\
\hline
\end{tabular}




\section{Results and discussion}

\section{a. Primers and genetic similarity}

Among the 28 RAPD primers, only four primers (P41, P60, P109 and P141) amplified the genomic DNA of test lines (Table 2). The percentage of primers that amplified the DNA was very low. These four primers showed polymorphism. We considered only those primers that could amplify the DNA of all samples with scorable bands (Figure 1,2). Most of the primers did not work probably due to the old or not related to rice genome or poor quality of template DNA. Polymorphism percentage of the tested RAPD primers are 90.0 in the study of [11] and 67 in [12]. In their study, with selected primers, sufficient polymorphism is detected to allow identification of individual varieties. RAPD analyses offer the greatest chance of detecting small genetic differences, since a larger component of the genome can be scanned than in other systems $[8,13]$. Primer 60 produced the highest number of bands (8). The highest number of present bands (6) was shown by primer 41 in 10 rice genotypes. The genetic similarity ranged from 0.00 to 0.96 . Mansara and Jarneli were the most similar landraces (0.96). The second most similar landraces were Tunde dhan and Krishnabhog. IR-24 showed the zero similarity coefficients with all genotypes. The zero similarity coefficient of Kali Marshi with Thapachini, Krishnabhog and Tauli indicates the most genetic dissimilarity. The similarity index between Chandannath-1 and Lalshar was also zero. A57-115-8 showed the zero similarity index with Chandannath-3. Two blast susceptible varieties, Mansuli and CO-39 have mostly the similar coefficients with all tested genotypes.

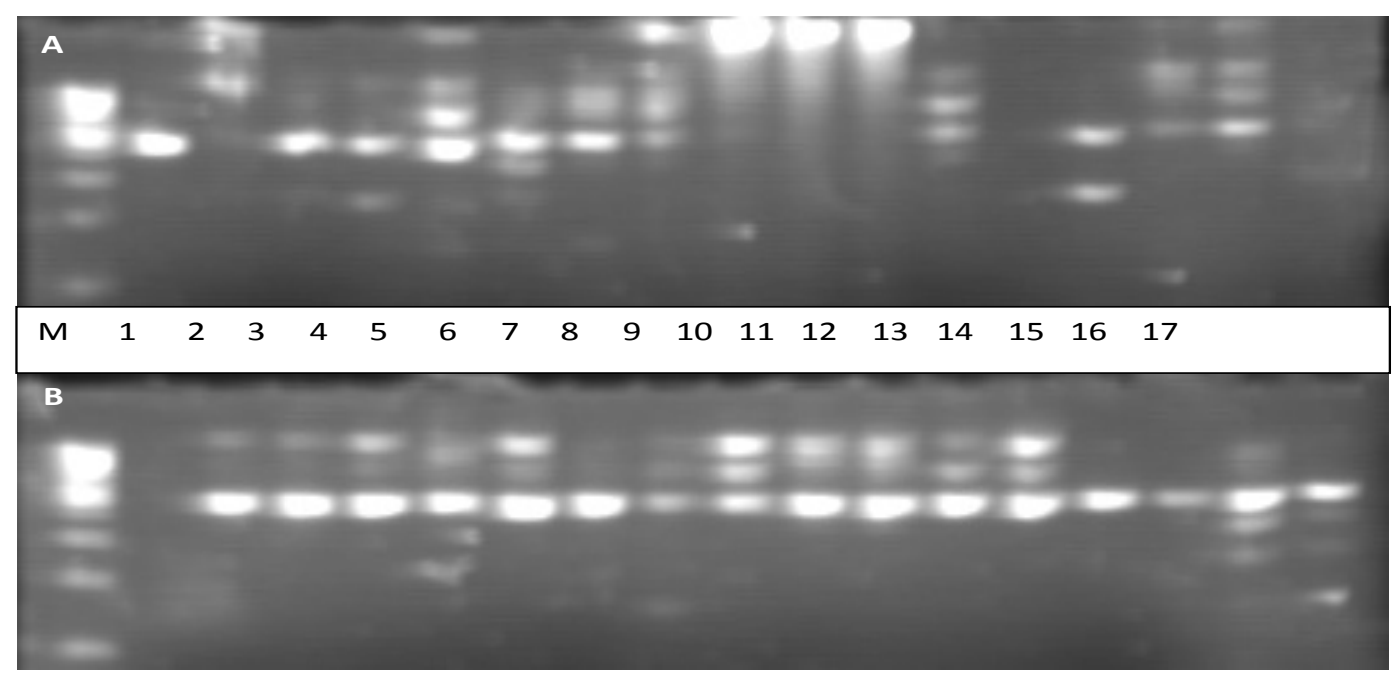

Fig.1. RAPD polymorphism of different rice genotypes with primer 141 
(M, marker; Sample A: 1, Kali Marshi; 2, Ghaiya dhan; 3, Dhokro dhan; 4, Maine Pokhreli; 5, Lekali dhan; 6, Hanse; 7, Pale dhan; 8, Bageri dhan; 9, Jethobor; 10, Pokhara Masino; 11, Chananchur; 12, Lalshar; 13, NR10315-145-2-3; 14, NR10286-6-3-2-2; 15, Manjushree-2 ; 16, NR10375-20-1-2; 17, Khumal 11. Sample B: 1, NR10353-8-2-1; 2, NR28518-3-2-3-1; 3, NR10276-15-2-3-3-2; 4, NR10414-25-2; 5, NR1041434-2-3; 6, Taichung-176; 7, Jumli White; 8, Chandhannath-1; 9, Chandhannath-3; 10, NR10276-9-3-3-3-2; 11, NR10285-29-3-1; 12, Sabitri; 13, IR-24; 14, A57-115-8; 15, CO 39; 16, Masuli;17, Check3 from Jumla, 2 from Humla and 3 Mugu).

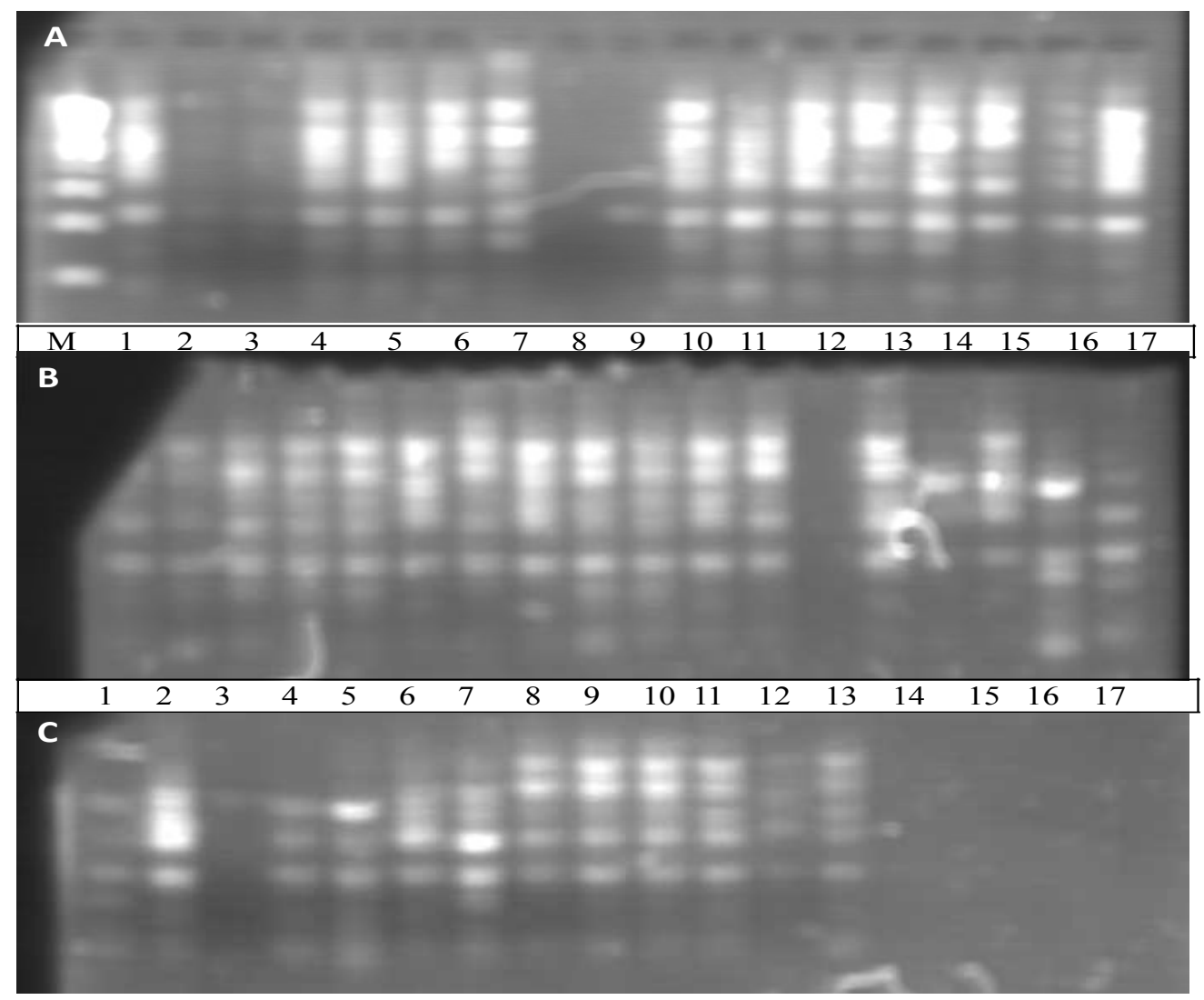

Fig.2. RAPD polymorphism of different rice genotypes with primer 41

(M, marker; Sample A: 1, *Krishnabhog; 2, *Thapachini; 3,Tauli; 4,Tunde dhan; 5, Rato dhan; 6, *Hansraj; 7, Mansara; 8,Chureno dhan ; 9, Anpjhutte; 10,Jarneli ; 11, Bhuwa dhan; 12, Jhuldhan; 13, *Pahele; 14,Radha-7; 15,Pakhe ; 16, Pranpyuri; 17, Madise. Sample B: 1, Kali Marshi; 2, Ghaiya dhan; 3, Dhokro dhan; 4, Maine Pokhreli; 5, Lekali dhan; 6, Hanse; 7, Pale dhan; 8, Bageri dhan; 9, *Jethobor; 10, *Pokhara Masino; 11, Chananchur; 12, Lalshar; 13, NR10315-145-2-3; 14, NR10286-6-3-2-2; 15, Manjushree-2 ; 16, NR10375-20-1-2; 17, Khumal 11. Sample C:1, NR10353-8-2-1; 2, NR28518-3-2-3-1; 3, NR10276-15-2-3-3-2; 4, NR10414-25-2; 5, NR10414-34-2-3; 6, Taichung176; 7, Jumli White; 8, Chandhannath-1; 9, Chandhannath-3; 10, NR10276-9-3-3-3-2; 11, NR10285-29-3-1; 12, Sabitri; 13, IR-24; 14, A57-1158; 15, CO 39; 16, Masuli; 17, Check3 from Jumla, 2 from Humla and 3 Mugu). * Aromatic rice.

\section{b. Cluster analysis}

The dendrogram generated by the RAPD analysis showed four distinct groups (Figure 3). IR-24 and Kali Marsi formed the separate individual cluster. Most of the genotypes fell in two clusters. Grouping of these genotypes based on the adaptation to agro-climatic zone was not observed, probably due to low percentage coverage of genome by four primers. Mansara and Jarneli were the most similar landraces followed by NR-10276-9 and NR-10285-20. Churenodhan and Pranpyuri were the most 
closely related with Masuli. The three blast resistance genes pyramided rice genotype,
A57-115-8 was genetically near with Anpjutte, Tauli and Thapachini.

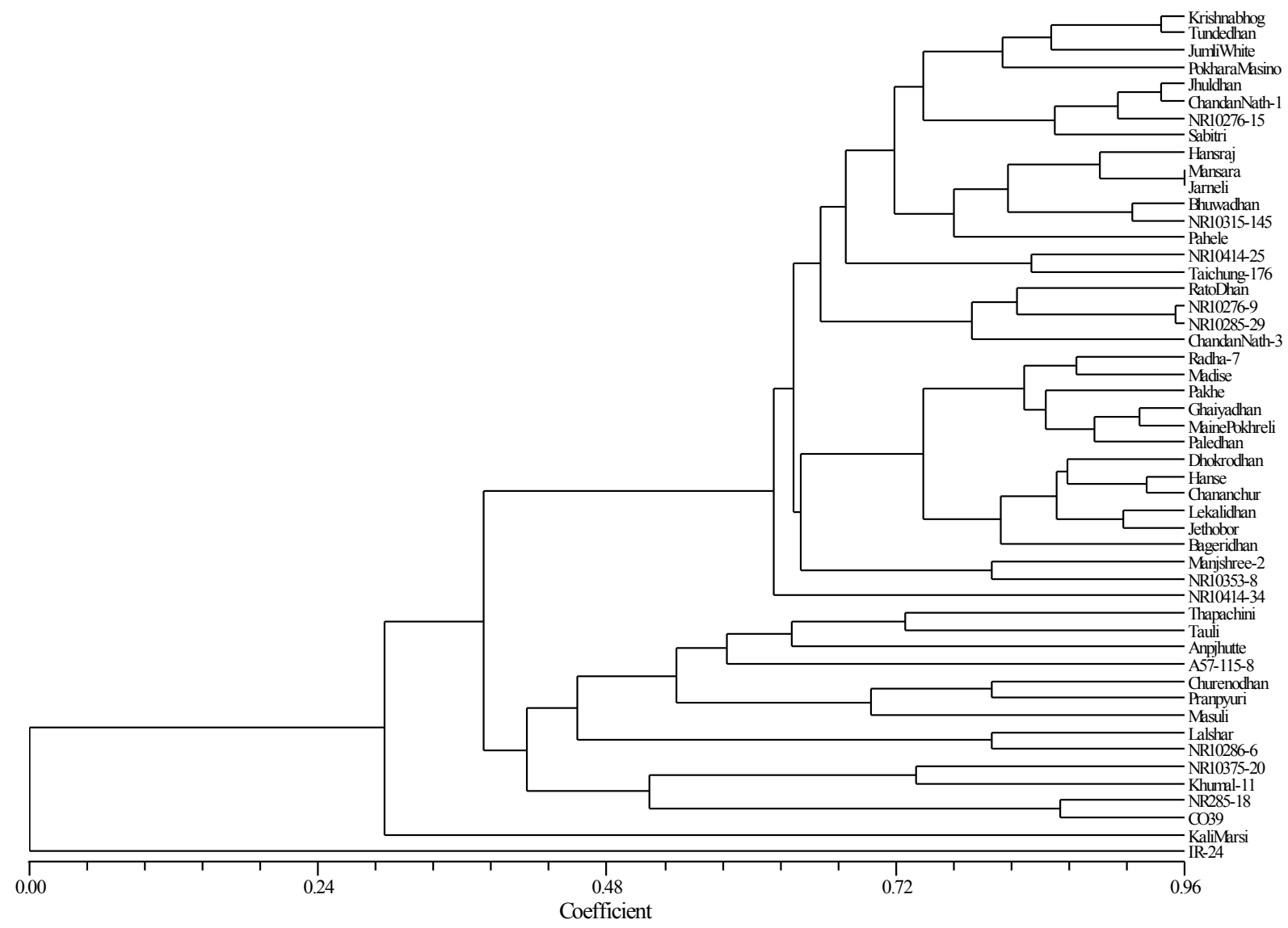

Fig.3. Clustering of 50 rice genotypes based on RAPD markers.

\section{c. Principal component analysis}

A scatter plot was drawn based on the similarity coefficients among the 50 rice genotypes (Figure 4). All genotypes except NR-285-18 fell in the second and third quadrant. Only one genotype NR-285-18 has fallen in the first quadrant by principal component analysis and the fourth quadrant was empty. The highest contribution in $\mathrm{PC} 1$ was from the second band of primer 41 (Table 3). Considerable overlapping among the various samples is evident, which suggests that genetic variation among them is rather narrow. Nevertheless, some rice samples appeared separate from the overlapping ones e.g. aromatic rice like Pahele, Jethobor, Maine Pokhreli, Pokhara Masino, and Hansraj. The level of 
distinctness versus overlapping was in good concordance with that of the cluster.

This preliminary genetic information could supplement for breeding and conservation works based on morphological markers. For increasing the value of genetic information derived from RAPD markers, number of primers should be increased. Choudhury et al. [14] suggest that a set of 10 primers can be employed for an initial assessment of genetic diversity in a large number of collections. Because of multilocus nature of RAPD, its use is considered more suitable for fingerprinting and genetic diversity measurement.

Table 3. Eigen vectors of RAPD primers based on 50 rice genotypes.

\begin{tabular}{|c|c|c|c|c|}
\hline Primer & Band & PC1 & $\mathrm{PC} 2$ & $\mathrm{PC} 3$ \\
\hline \multirow[t]{6}{*}{ P41 } & 1 & -0.363 & 0.203 & -0.123 \\
\hline & 2 & -0.374 & 0.217 & 0.019 \\
\hline & 3 & -0.300 & 0.370 & 0.046 \\
\hline & 4 & -0.371 & 0.247 & -0.012 \\
\hline & 5 & -0.299 & 0.240 & 0.078 \\
\hline & 6 & -0.148 & 0.174 & 0.536 \\
\hline \multirow[t]{8}{*}{ P60 } & 1 & -0.225 & -0.284 & -0.022 \\
\hline & 2 & -0.252 & -0.357 & -0.071 \\
\hline & 3 & -0.167 & -0.200 & -0.327 \\
\hline & 4 & -0.096 & -0.053 & -0.172 \\
\hline & 5 & -0.097 & -0.153 & 0.029 \\
\hline & 6 & 0.197 & 0.268 & -0.034 \\
\hline & 7 & 0.124 & 0.071 & 0.083 \\
\hline & 8 & 0.065 & 0.063 & -0.037 \\
\hline \multirow[t]{7}{*}{ P141 } & 1 & 0.085 & 0.124 & -0.060 \\
\hline & 2 & -0.157 & -0.257 & 0.472 \\
\hline & 3 & -0.112 & -0.321 & 0.372 \\
\hline & 4 & -0.083 & -0.143 & 0.198 \\
\hline & 5 & 0.068 & 0.016 & 0.048 \\
\hline & 6 & -0.045 & -0.090 & 0.059 \\
\hline & 7 & -0.009 & 0.003 & 0.032 \\
\hline \multirow[t]{3}{*}{ P109 } & 1 & -0.202 & -0.097 & -0.221 \\
\hline & 2 & -0.199 & -0.135 & -0.230 \\
\hline & 3 & -0.180 & -0.175 & -0.157 \\
\hline Eigenvalue & & 1.062 & 0.629 & 0.396 \\
\hline Proportion & & 0.243 & 0.144 & 0.090 \\
\hline Cumulative & & 0.243 & 0.386 & 0.477 \\
\hline
\end{tabular}




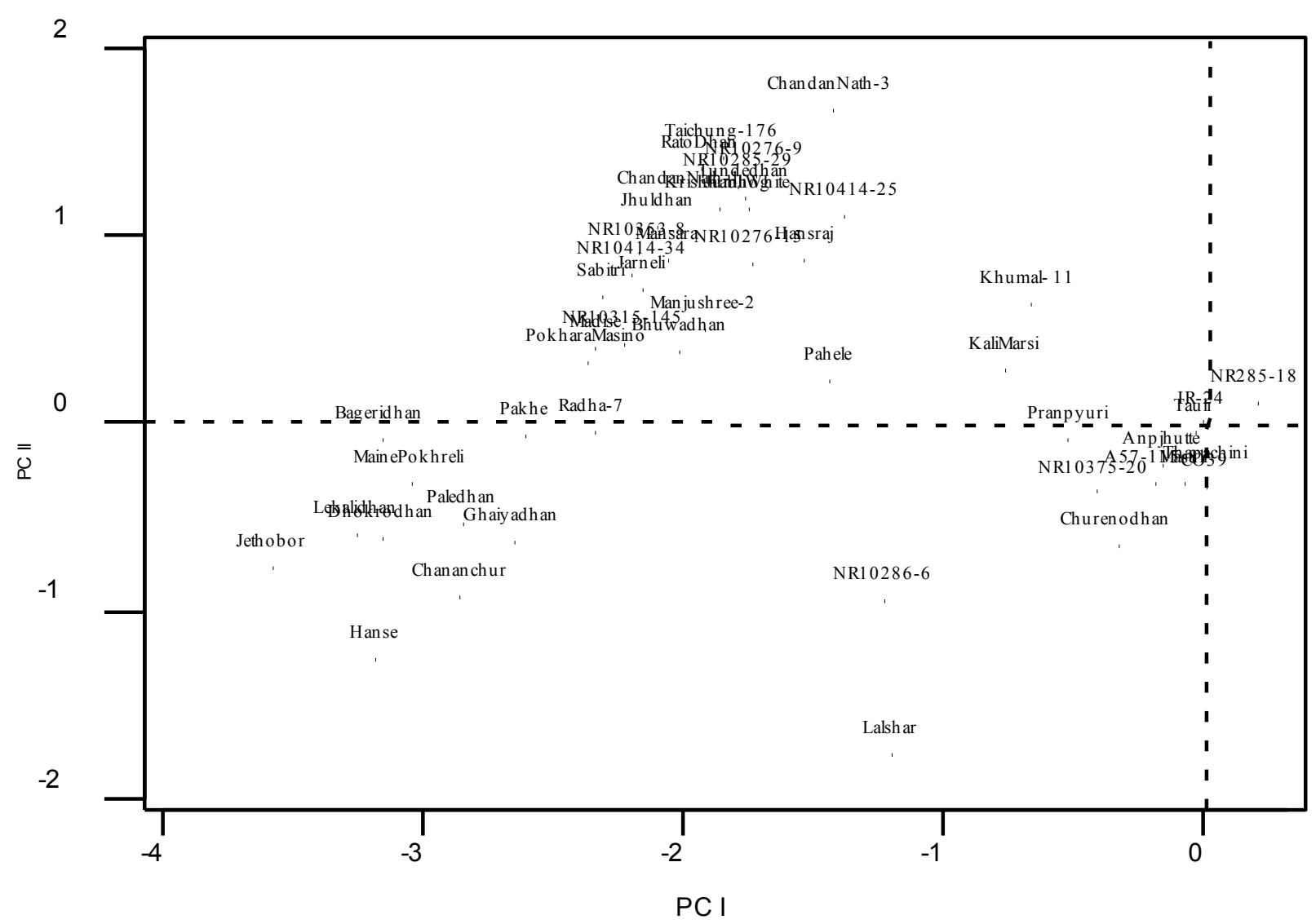

Fig.4. Scatter plotting of 50 rice genotypes based on four RAPD markers. 


\section{References}

1. Joshi BK: Rice gene pool for mid and high hills and its conservation in Nepal. In Agricultural Research for Enhancing Livelihood of Nepalese People. Proceedings of 2nd SAS-N Convention, 30 July - 1 Aug 2003; Kathmandu. edited by Joshi BK, Joshi SL, Paudyal KP2004:252-264.

2. Joshi BK: Rice gene pool for Tarai and Inner Tarai areas of Nepal. Nepal Agric. Res. J. 2005, 6:10-23.

3. Williams JGK, Kubelik AR, Livak KJ, Rafalski JA, Tingey SV: DNA polymorophisms amplified by arbitrary primers are useful as genetic markers. Nucleic Acids Res. 1990, 18:6531-6535.

4. Fuentes JL, Escobar F, Alvarez A, et al. Analysis of genetic diversity in Cuban rice varieties using isozyme, RAPD and AFLP markers. Euphytica 1999, 109:107-115.

5. Mackill DJ: Classifying Japonica rice cultivars with RAPD markers. Crop Sci. 1995, 35:889-894.

6. Virk PS, Newbury HJ, Jackson MT, PordLloyd BV: The identification of duplicate accessions within a rice germplasm collection using RAPD analysis. Theor. Appl. Genet. 1995, 90:109-155.

7. Karp A, Kresovich S, Bhat KV, Ayad W, Hodgkin T: Molecular tools in plant genetic resources conservation: $A$ guide to the technologies. IPGRI Technical Bulletin No. 2. IPGRI, Rome; 1997.
8. Ren F, Lu BR, Li S, Hunag J, Zhu Y: A comparative study of genetic relationships among the AA-genome Oryza species using RAPD and SSR markers. . Theor. Appl. Genet. 2003, 108:113-120.

9. Sul IW, Korban SS: A highly efficient method for isolating genomic DNA from plant tissues. Plant Tissue Culture Biotechnol. 1996, 2:113-116.

10. Rohlf FJ: NTSYS-pc. Numerical taxonomy and multivariate analysis system. Version 1.8. New York: Exerter Software; 1993.

11. Ravi M, Geethanjali S, Sameeyafarheen F, Maheswaran M: Molecular marker based genetic diversity analysis in rice (Oryza sativa L.) using RAPD and SSR markers. Euphytica 2003, 133:243-252.

12. Ko HL, Cowan DC, Henry RJ, et al. Random amplified polymorphic DNA analysis of Australian rice (Oryza sativa L.) varieties. Euphytica 1994, 80:179-189.

13. Morell MK, Peakall R, Appels R, Preston LR, Lloyd HL: DNA profiling techniques for plant variety identification. . Aust. J. Exp. Agric. 1995, 35:807-819.

14. Choudhury PR, Kohli S, Srinivasan K, Mohapatra T, Sharma RP: Identification and classification of aromatic rice based on DNA fingerprinting. Euphytica 2001, 118:243-251. 